\title{
Smart Sovereignty: The Security Shield for Smart Society 5.0
}

\author{
Mohammad Aldabbas, Stephanie Teufel, Bernd Teufel, Virgile Pasquier \\ International Institute of Management in technology (IIMT), \\ University of Fribourg \\ Switzerland
}

\begin{abstract}
Transformation of human societies is inevitable. Soon humanity will witness Society 5.0. The Super Smart Society is pushed and charged with technological growth and revolutions. This will inevitably present both opportunities and challenges affecting most aspects of our lives. In this paper, the authors discuss the actions required to mitigate potential risks in this process. With that in mind, the authors are introducing a novel concept: Smart Sovereignty. Smart Sovereignty aims to shift the position of power away from governments and large corporations, and directly and indirectly empower individuals to control and lead the change through new organizations, NGOs, and NPOs. This new concept opens the doors for a vast research field that touches our security directly. Finally, the authors propose a framework enabling society to reach and maintain a state of sustainable Smart Sovereignty.
\end{abstract}

\section{Introduction}

The impact of digitalization on our daily lives is vast, all-encompassing, and does not show any signs of abatement in the short or medium term. Our dependency on technology, both in form of material and digital artifacts, has become so great that even basic daily tasks such as movement from point A to point B or the purchase of a transportation ticket are routinely executed utilizing smartphones and other forms of wearable technologies.

In addition to being a simple yet accurate example of technological dependency, the above highlights the potential for both deliberate and accidental developments of new forms of technology-based addictions [1]. This issue leads the authors towards several yet unresolved questions: why does this matter? and what is the problem with so many people being so dependent on technology? The answer is quite simple. In the current example of traveling, corporations that manage public transportation (SBB in the case of Switzerland) and navigation providers such as Google, hold and process a massive number of customers' data.

Providing corporations with so much insight into individuals' data provides them with access to personal information such as where a person lives, what time they wake up, where they work when they go to sleep, and so on. Similarly, supermarkets and other stores keep records of what we buy and what we consume. Pharmacies and hospitals store our health records. The list keeps going on and on, leading us to question if there is any privacy left at all.

Between corporations and governments pushing digitalization for economic and efficiency reasons, and individuals heavily [2] relying on technology for convenience reasons, there is very little room left for preserving privacy.

In the age of the fourth Industrial Revolution (4IR), data privacy is just one of many aspects that societies should be conscious of. The authors have published an overview paper on the risks driven by the intensification of technology that has the potential to threaten Smart Societies [3]. As with every previous stage of technological development, it is also true for 4IR, -based on buzzwords such as digitalization, artificial intelligence, or deep learning- that new technologies can be used to the advantage and benefit for everyone in their day-to-day activities, productivity at work, access to information, ease of use of goods and services. On the other hand, if there is no critical examination of the associated capabilities, technology can also open the doors to issues surrounding privacy, cultural autonomy, manipulation, fake news, etc.

The work of [3] differentiated between technological challenges and threats, and societal risks. Table 1 shows some of the identified threats, which are being highlighted due to the mass dependence on new and smart technologies. Human society is at the point where we have become very reliant on such technologies and profoundly locked up in the system of convenience and dependency from which is very hard to break free [3].

The interaction between people and machines is increasing. Data is constantly being collected, sometimes without knowing what it is going to be used for, bearing in mind that more than a third of the world's population uses social media to connect and communicate [4]. 
Table 1: Concerns for society and technology in Smart Societies

\begin{tabular}{|c|c|}
\hline Concern for Society & $\begin{array}{l}\text { Concern for Technol- } \\
\text { ogy }\end{array}$ \\
\hline Data protection & Data heterogeneousness \\
\hline $\begin{array}{l}\text { Governmental surveil- } \\
\text { lance }\end{array}$ & $\begin{array}{l}\text { Hardware environment } \\
\text { compatibility }\end{array}$ \\
\hline Public manipulation & $\begin{array}{l}\text { Security of data and } \\
\text { cyber security }\end{array}$ \\
\hline Unemployment & $\begin{array}{l}\text { Digital trust and E-vot- } \\
\text { ing }\end{array}$ \\
\hline Cyber bullying & Digital rights \\
\hline
\end{tabular}

Besides, technologies such as robotics, 3D printing, genetic engineering, quantum computing artificial intelligence, deep learning, blockchain, and many others are shaping the future of the new human society and are going to have a fundamental impact on the development of society and economy [5]. The mentioned arguments above show that technologies have a strong potential to drastically influence individuals' personal lives, as well as have an impact on how humans interact with each other. In this case, these innovations can be considered disruptive innovations that can have an impact on our way of living [6].

To be clear, technological progress can be a great asset to a society, but this requires considerate and responsible use of the technologies, both on an individual level and the level of the society. The current concern is that the future does not look very promising if these risks and threats, which have already created considerable issues, are not addressed properly, especially having in mind that they are progressively becoming complex. There is an absolute and immediate necessity to introduce a novel concept that will allow people to restore their sovereignty and take over control, thus preserving and protecting human society from being eradicated by technology.

\section{Necessary Actions}

Following discussions on a variety of challenges and threats to Smart Society and presenting lists of potential problems, the authors are going to focus on proposing necessary actions and steps required to adequately face and appropriately react to the threats.

Unfortunately, the answer is not straightforward, as the problem itself is very complex to comprehend. Certain things should be taken into consideration when thinking of potential actions, such as:

- Acting on a variety of levels from educational, economic, and environmental to governmental and industrial; Keeping stakeholders, ranging from members of the public and citizen activists to politicians and governments accountable and responsible for their actions;

- Increasing the range of discipline and expertise;
- Planning for and being able to adequately respond to potential conflicts of interests among stakeholders.

The main priority is to ensure an acceptable level of data, privacy, assets, and information protection. The authors suggest that an effective way to limit the consequences of the risks is to introduce a method of monitoring and controlling that is aimed to empower the people to observe, oversee and intervene in critical situations. This needs to be in the form of collective actions and organized groups since separate individuals are incapable of handling such tasks and responsibilities, thus making people the real sovereigns of their data, privacy, and anything else that has the potential to threaten society. For instance, the Internet of Things (IoT) is heavily challenging the concept of privacy because of the amount of data collected through technology and other smart devices connected to the internet [7].

The authors of this paper are proposing that the new concept is named Smart Sovereignty. It is aimed to provide a detailed description, as well as the background for the Smart Sovereignty, how it is supposed to function, how to measure and improve its success.

Governmental surveillance practices in countries like China [8] and Russia [9] have always been a real concern for western societies of Europe and the US. The concept of privacy and data security is subject to close observation by authorities, which considerably changes the understanding and interpretation of these concepts. The level of freedom of speech and upholding fundamental human rights are at times questionable. Intervening in other country's internal affairs is not considered as possible since such actions would bring the country's sovereignty into question, as the authors will discuss in the following chapter. However, it is possible to drive change in another country without threatening its sovereignty through a combination of political pressure, international treaties, and agreements.

It is vital for economies, that decision-makers thoroughly analyze the costs and benefits of implementing modern technologies that have the potential to create redundancies among low-skilled workers. Despite what the Japanese government promises in their attempts to promote Super Smart Society -Society 5.0- [10], modern technologies are unlikely to have the capacity to create new jobs and help drive down unemployment rates [11]. On the one hand, introducing such technologies can have many positive impacts when it comes to improving productivity, competitiveness, lowering costs, and so on. New businesses will emerge, and existing industries will prosper due to advanced technology [12]. Potential job losses can have a severe negative impact on society in the middle and long term. Claims that such transformation is reshaping the economy will create new jobs and opportunities tell only half of the truth. Technology will create new jobs, but will also render some 
existing jobs redundant [13]. That means, that "the risk that new technologies will displace jobs, and potentially eliminate some of the current categories of employment, has to be taken seriously" [14]. Some researchers anticipate that the negatives of lost jobs will far outweigh the positives of created jobs. Artificial Intelligence (AI) will only speed up the automation of jobs and create severe unemployment issues for society [15]. This phenomenon will increase gaps in the societies, with the most noticeable impacts on the middle class, and deepen the issues of income inequality [16].

\section{Historical Overview of Sovereignty}

\subsection{Origins}

The concept of sovereignty was initially developed during the 17 th century and usually refers to an international doctrine of non-interference in internal matters of another state [17]. However, Glanville describes an evolving concept of "sovereignty" that was initially considered as the right to wage war. That right belonged to the prince only because they had the authority to decide if a war was just or, more precisely, if another group had violated the laws of nature. From that moment, the sovereign (whether that is a prince of any other kind of government) had the sovereignty over their land, as well as the responsibility to interact with other sovereigns. This definition of sovereignty is both internal (representing a country in international affairs) and external as countries should interact with the sovereign and refrain from influencing the internal affairs of another country.

The first mentions of this type of sovereignty appeared during the 17 th century and evolved into a concept of non-interference during the 18th century, but still included the right for states to "rescue oppressed people who implore their assistance" [17]. Following the French revolution, "the right to intervene belongs as clearly and indisputably to every government which finds itself in danger of being drawn into the revolutionary maelstrom, as it does to any individual who must put out a fire in his neighbor's house if it is not to spread to his own" [18]. This shows the limits of non-intervention when the internal affairs of a certain country threaten the peace and well-being of another.

After those troubled times in Europe, the principle of non-intervention was also gradually consolidated as a right of sovereignty in international legal commentaries through the course of the 19th century [17]. After the two World Wars, the concept of non-intervention has been challenged by the human rights dimension where intervention in the internal affairs of another state could be justified if that state infringes human rights. In that perspective, a state can interact with the citizens of another state, overriding the authority of the government of that state. The modern concept of sovereignty was finally formalized by the League of Nations and then later by the United $\mathrm{Na}-$ tions Organization: "No state has the right to intervene, directly or indirectly, for any reason whatever, in the internal or external affairs of any other state". Consequently, armed intervention and all other forms of interference or attempted threats against the state or its political, economic, and cultural elements, are condemned [19]. In 2011, UN Security Council appealed to the "responsibility to protect" concept and authorized the use of "all necessary measures" to protect civilians from the threat of mass atrocities in the sovereign state of Libya [20].

In conclusion, it is fair to say that the development of sovereignty has not been linear throughout the centuries. One study [21] describes how sovereignty went back and forth between being state-centric during conflicts like the Napoleonic wars or the Cold War, and nation-centric during quieter times. The concept of sovereignty is consequently to the concept of NationState, its legitimacy to act as an authority on its territory but also to interact with foreign states.

\subsection{Nation-states interaction}

From the commonly accepted definition [21] a nation-state is a territory on which lives a certain group of people organized in a political entity. In figure 1, the authors try to present how a system of interactions between nation-states traditionally function under non-intervention treaties, while figure 2 shows the interaction between the states in a digital society.

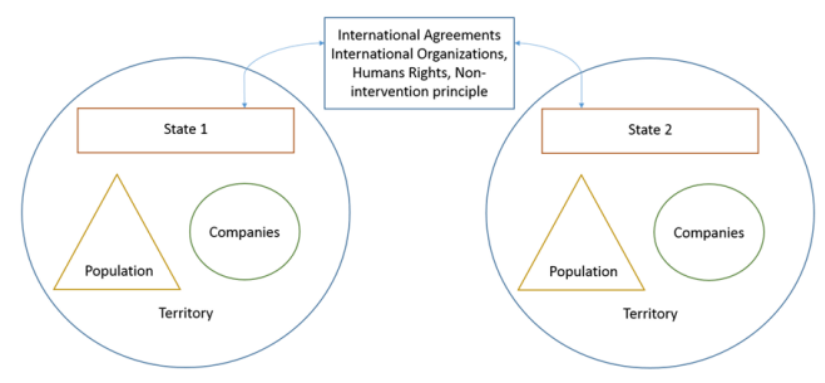

Figure 1: State interaction within traditional sovereignty

Sovereignty is being challenged since the system evolved through the increase of international communication, which is enabling direct contact and influence between different entities in different nationstates. In the second example, a slightly more complex situation can be observed, where companies with their headquarters in Country 1 interact with the State of Country 2, sells products or services to the population, and trades with other companies. Additionally, State 2 tries to influence the population of Country 1 to pro- 
mote its own goals. This situation is fictional but accurately depicts how traditional understanding of sovereignty can and will be challenged.

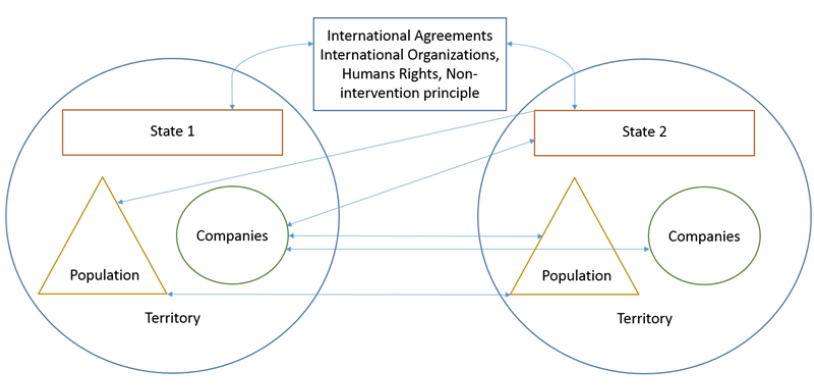

Figure 2: State interaction in a digital society

\section{Features of Smart Sovereignty}

Before outlining and defining Smart Sovereignty, the authors aim to define and determine the main areas of focus. Published studies highlight data sovereignty, internet sovereignty, digital ethics, and trust as core features for the application of Smart Sovereignty due to their direct relevance to both individuals and society.

Data is the base of Smart Society [3] and the platforms are seen as the gate between the virtual and real world. For more insight about these platforms, we refer the reader to [3]. The terms of internet sovereignty and cyberspace sovereignty are concepts that have already been present for some time now, with several studies and researchers investigating and discussing their importance [22].

In liberal societies, the Internet is supposed to spread liberty and freedom, however, this is not always the case. In countries that practice what is called Authoritarian Informationalism, the Internet is in the function of establishing and broadening the government's control and spying on the citizens, as well as expanding its authority [8]. The concept of digital ethics in Smart Society deals with the impacts of the transformed digital information and communication on society. This address matters related to privacy, internet addiction, division, surveillance, etc. [23]. So, the challenge that the Smart Society is facing is not a matter of innovation of technology, but the challenge of governance and controlling the digital aspects [24].

The importance of trust stems from the fact that it has a crucial role for people to adopt technologies like IoT and its services [25]. Besides, the users' trust is vital for the acceptance and appliance of technologies and a key to success for Smart Society. Smart Sovereignty is all about digitalization and reforming the understanding of the purpose of digitalization. The interconnection between people and smart devices around them through the latest technologies is not a passing trend, but a new lifestyle [26]. Digitalization is an instrument in a society where people are still the key players attempting to form a super Smart Society [27]. The relevance of digitalization is based on the massive change that it brings in terms of technical innovations, optimization, and social development [26]. Restructuring the way digital technology operates is a necessity [28]. Factors such as technology development processes, economic incentives, the increased transparency of machine learning, and data collection should be addressed and focused on for a sovereign society. AI needs to be built in a way that it supports human goals driven by human values [28]. The definition of AI should be reviewed to ensure that society will benefit from machines capable of learning by observation [29].

Defining the environment of sovereignty depends on describing the political, ecological, and technological environment of the country where it will be applied. This implies that, as a result, the characteristics of sovereignty may differ from country to country. Nonetheless, global basic standards can still be defined, and only at a later point, these can be adjusted according to the needs and characteristics of the individual country of implementation.

\section{Domains and Applications of Smart Sovereignty}

This section attempts to highlight the domains in Smart Society where Smart Sovereignty can be applied. We consider that data protection and digitalization are the umbrellas for Smart Sovereignty under which come the main fields of application. As presented in Figure 3 Smart Society healthcare, energy sharing, and mobility are our focus of Smart Society (obviously, there are other important dimensions). The following paragraph will dig deeper into the justification and arguments for focusing on these areas. The importance of data protection has already been discussed previously, for more insight see [3]. Data is the foundation of Smart Society, and it goes through five processes: collection, communication, storage, usage, and destruction. Omitting the significance of data is a fatal error for Smart Sovereignty. The authors have already in this paper addressed the relevance of digitalization in more detail.

The significance of healthcare, energy sharing, and mobility:

Healthcare services and providers are increasingly relying on robots, particularly in surgeries. However, one study [30] has exposed significant gaps when it comes to protections from basic forms of cyber-attacks. Security gaps have been identified both around the protection of patients' private data, as well as around the configurations of the software that runs the robot during surgery. For instance: the point's coordinates of inserting the knife during surgery can be easily manipulated by third parties in an attempt at a malicious attack. The present situation highlights several 
shortcomings that require urgent attention and need to be appropriately dealt with to be ready for Society 5.0.

One of the main characteristics of the Smart Society will be the use of/reliance on sensors, information, and communication technologies. The available technology will not only enable innovative energy sharing concepts such as Crowd Energy [31], but also energy production and transformation which relies on smart grids. This means that any weakness in the grids' security may potentially threaten the integrity of the energy exchange. A previous study by [26] showed that in the energy domain, crowd applications can be created in a way that turns crowds into enablers of Smart Society, which achieves one of the main goals of Smart Sovereignty.

The aspect of mobility in Smart Societies is very important and rather complex [3] as most of the demand for mobility is reliant on sensors and information and communication technology (SICT).

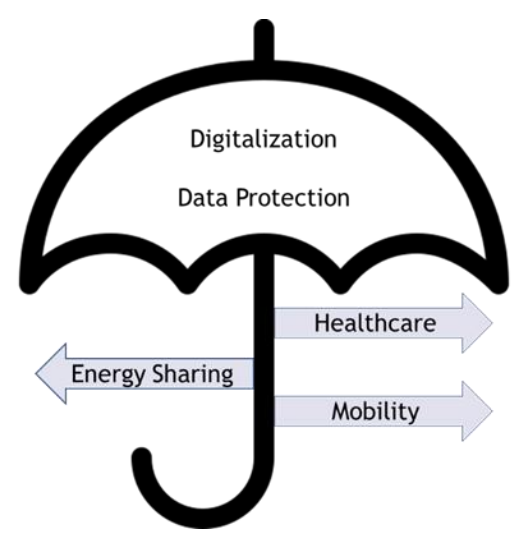

Figure 3: Domains and application of Smart Sovereignty

To put all these elements together, the authors start from the previous work of Smart Framework [32] and the definition of Smart. The Smart Framework provides a logical approach to integrate Smart Sovereignty. Figure 4 shows the application of Smart Sovereignty in Smart Framework.
Sustainable welfare can be achieved by applying Smart Sovereignty and coordinating all the activities through all layers of Smart Society 5.0. The aim is to ensure sovereignty for society, services, environment, and technology. Integrating all aforementioned aspects will mitigate the risks and reduce the threats to the future society, as well as improve the outcomes of future development process towards increased Smart Sovereignty. Smart Sovereignty will need to be applied on different levels: communities, organizations, and institutions.

\section{Definition}

Before defining Smart Sovereignty, it is important to first define the term that will be used in the definition. In the following text when referring to societal security the authors mean security and safety of the society from the risks and the threats that are discussed in the introduction. This should not be confused with any other expression used to broadly determine societal security. Based on this, Smart Sovereignty is intended to ensure and maintain societal security.

The concept and definition of some technologies should be reviewed and improved to attain Smart Sovereignty. The understanding and purpose of AI, IoT, and deep learning should be redefined [28] so that they are in the function of the prosperity of individuals in the Smart Society, rather than for the profit of the large corporations. The mission of Smart Sovereignty is to create a roadmap to lead society into a more secure environment in the light of the previously discussed aspects. This can be achieved by focusing on technology, education, and governance, to ensure that individuals are the real sovereigns and have control over their lives and future. Smart Sovereignty puts people in the center, with a strong focus on the best interest and prosperity of the environment, society, and individuals. Focusing on values, ethics, and rights especially from a digital point of view is at the core of the 4IR [33], which will pave the path for Smart Sovereignty to shape the future of the Smart Society.

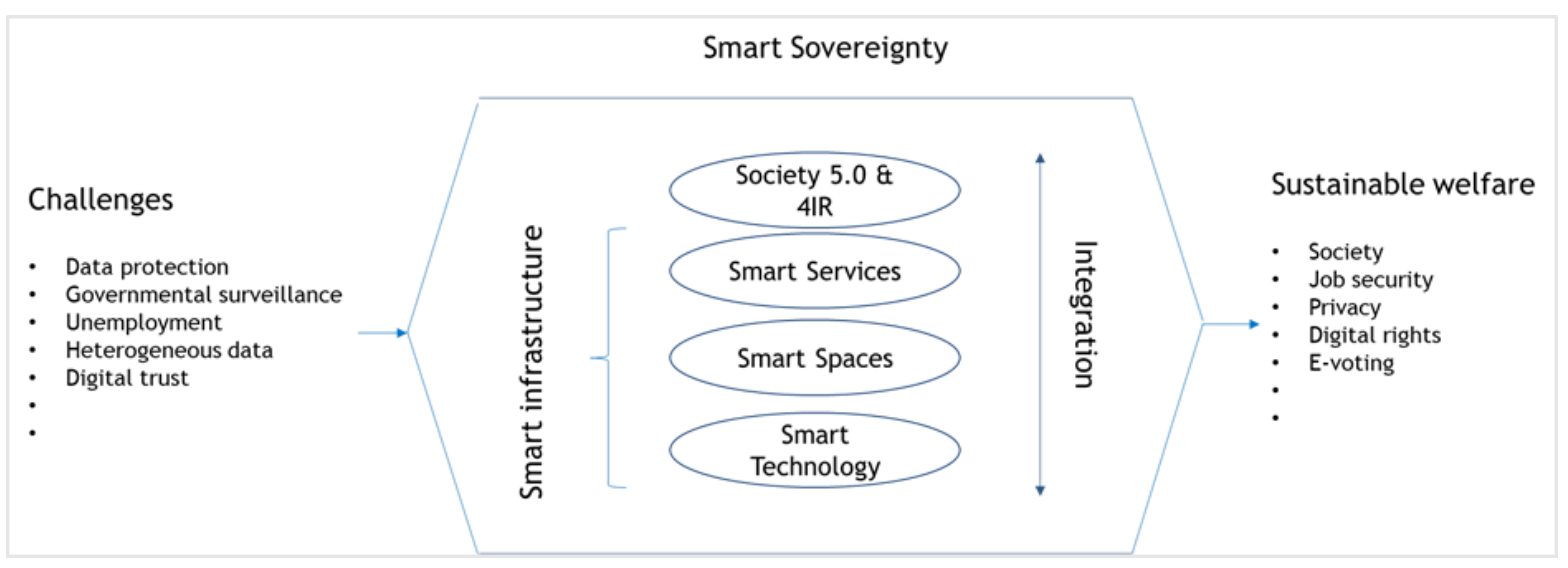

Figure 4: Smart Sovereignty Framework in Smart Environments 
A new approach is required to address future challenges and involve policy makers, educational institutes, and any other affected parties. The authors have identified a gap and a requirement to define a roadmap and a concrete plan to reach the desired outcomes. This brief description of the aims and tasks of Smart Sovereignty allows us to define Smart Sovereignty as:

\section{"a self-governing right of individuals in Smart Soci-} eties to retain their societal security."

\section{Discussion}

Sovereignty in the presented context is digital in nature and far from the political sphere. It is not only about rights; it is also the duties of the individuals to make them real sovereigns in Smart Societies like Society 5.0 and 4IR. The domains of application are mainly: energy, mobility, and healthcare, to reach societal security. Smart Sovereignty can be an international term with its specifications to fit the requirements of different countries and nations. It resembles a clash between humans and machines to exploit the potential of all technologies for the sake of human values. It is meant to be a global necessity for popular sovereignty to be the foundation of Smart Societies.

There is a requirement to raise awareness around Smart Sovereignty, which needs to be driven by organized groups, rather than individuals themselves. Raising awareness needs to be a systematic and strategic effort, rather than expecting it to organically appear among individuals, organizations, and administrators. These organizations should represent the people and have legal backgrounds in terms of support and expertise. The intended outcome of Smart Sovereignty is the maintenance of an individual's societal security in Smart Societies. Monitoring technology by using governance method is required to prevent Smart Societies from being machine focused, which is one of the challenges that Smart Societies will need to overcome.

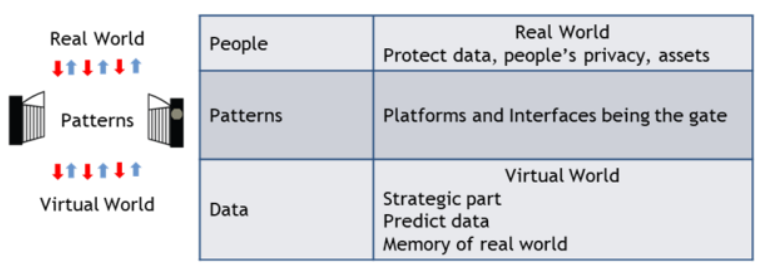

Figure 5: Interaction between Real World and Virtual World

The core element of Smart Sovereignty is data, and data is the foundation of the virtual world. Figure 5 shows the interaction between the real and the virtual world, and how platforms are the gateway between two worlds. Actors (people) in the real world are connected to the data in the virtual world via platforms and patterns that are under the sole control of large corporations, states, and/or government agencies. Individuals and by extension the societies are dependent and at the mercy of these pillars of power, which is not a desired and healthy environment for a Smart Society.

Given that most data patterns are currently owned by a large corporation, the authors recognize the need for new patterns. Envisioning and designing such patterns require extensive financial resources and protection. Key responsibilities to achieve the Smart Sovereignty framework are to develop, improve, use, and protect new patterns to achieve a Sustainable Smart Sovereignty as shown in Figure 6.

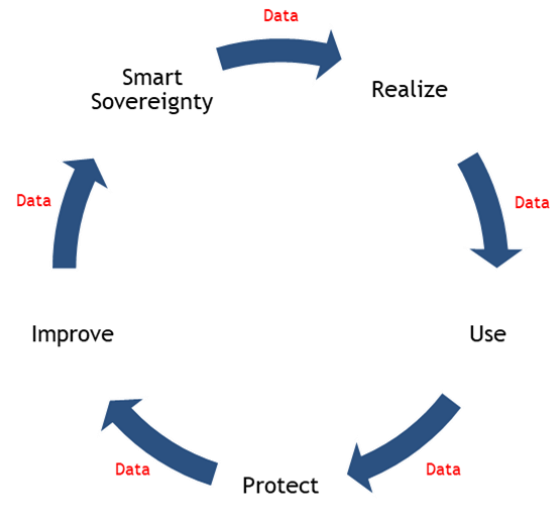

Figure 6: Sustainable Smart Sovereignty Framework

The cycle of achieving, maintaining, and improving sustainable Smart Sovereignty starts from realizing Smart Sovereignty by applying it in Smart Society, then ensuring that people are the real sovereigns in their society and that they have the power to observe, control, and be able to influence the direction of the technology development, so it serves their interest as humans. Some flaws in the application of Smart Sovereignty might become evident as time goes and circumstances change, which calls for the system to be flexible and accept improvements as an integral phase of the life cycle of Smart Sovereignty. The new inputs and adjustments will affect the nature and probably the application of Smart Sovereignty, at which point a revised version of Smart Sovereignty is ready to be implemented in the society.

Finally, it is important to note that this framework of sustainable Smart Sovereignty is only a primary version and subject to change throughout the evolution of a concrete improvement of Smart Sovereignty.

\section{Conclusion}

This paper addressed the concerns that arise with the dawn of Smart Society from a societal perspective 
and omitted technological development. First, the authors showed the core role that data plays in smart societies and how this influences the lives of individuals. Later, the authors emphasized the urge to take action to limit the harm that can accompany Smart Society by introducing a new concept. The main purpose of the paper is to introduce a novel concept of Smart Sovereignty that aims to make people the real sovereigns in the new Smart Society through new legal organizations. A brief history of sovereignty was discussed, and the transformation of the definition of sovereignty from pure political into social and technological features.

After the definition, the authors proposed a framework to maintain and improve Smart Sovereignty to make it sustainable within the society and for the people. Future research should try to answer questions around quantifying and measuring sovereignty. It is essentially the question that measures and determines the success or failure of Smart Sovereignty. The maturity and usability of sovereignty is another important matter that would require looking into in the future. Additionally, identifying who is the sovereign individual in the future Smart Society is another interesting topic to investigate; what are the characteristics of these individuals, and what roles they play for sovereignty starting with the rights and obligations of individuals in a modern smart nation?

\section{Acknowledgements}

This work was supported by the Canton of Fribourg, Switzerland, through the Smart Living Lab project at the University of Fribourg.

\section{References}

[1] T. Takahashi, "Behavioral Economics of Addiction in the Age of a Super Smart Society: Society 5.0," Oukan, vol. 12, no. 2, pp. 119-122, 2018, doi: 10.11487/trafst.12.2_119.

[2] M. Warkentin and R. Willison, "Behavioral and policy issues in information systems security: the insider threat," European Journal of Information Systems, vol. 18, no. 2, pp. 101-105, 2009.

[3] M. Aldabbas, X. Xie, S. Teufel, and B. Teufel, "Smart Society Challenges: from Technical and Societal Perspectives," in Proc. 2020 International Conference on Smart Grid and Clean Energy Technologies (ICSGCE 2020), Sarawak, Malaysia, 2020.

[4] P. Prisecaru, "Challenges of the fourth industrial revolution," Knowledge Horizons. Economics, vol. 8, no. 1, p. 57, 2016.

[5] M. Fukuyama, "Society 5.0: Aiming for a New HumanCentered Society," Japan SPOTLIGHT, pp. 47-50, 2018.
[6] A. A. Rahman, U. Z. Abdul Hamid, and T. A. Chin, "Emerging Technologies with Disruptive Effects: A Review," PERINTIS eJournal, vol. 7, no. 2, pp. 111-128, 2017.

[7] X. Caron, R. Bosua, S. B. Maynard, and A. Ahmad, "The Internet of Things (IoT) and its impact on individual privacy: An Australian perspective," Computer Law and Security Review, vol. 32, no. 1, pp. 4-15, 2016, doi: 10.1016/j.clsr.2015.12.001.

[8] M. Jiang, "Authoritarian informationalism: China's approach to Internet sovereignty," SAIS Review of International Affairs, vol. 30, no. 2, pp. 71-89, 2010.

[9] N. Maréchal, "Networked authoritarianism and the geopolitics of information: Understanding Russian Internet policy," Media and Communication, vol. 5, no. 1, pp. 29-41, 2017.

[10]. Cabinet Office, Government of Japan, Science and Technology Policy. Council for Science, Technology, and Innovation Society 5.0. [Online]. Available: https://www8.cao.go.jp/cstp/english/society5_0/index.html (Accessed: 25 June, 2019).

[11] G. Graetz and G. Michaels, "Is modern technology responsible for jobless recoveries?". American Economic Review, vol. 107, no. 5, pp. 168-173, 2017.

[12] J. Schmandt, R. Wilson, S. E. Smith, and B. H. Muller, Promoting high technology industry: Initiatives and policies for state governments: Routledge, 2019.

[13] R. W. Rumberger, "High technology and job loss," Technology in Society, vol. 6, no. 4, pp. 263-284, 1984, doi: 10.1016/0160-791X(84)90022-8.

[14] M. Annunziata and H. Bourgeois, "The future of work: how G20 countries can leverage digital-industrial innovations into stronger high-quality jobs growth," Economics EJournal, 2018, doi: 10.5018/economics-ejournal.ja.2018-42.

[15] G. Su, "Unemployment in the AI Age," AI Matters, vol. 3 , no. 4, pp. 35-43, 2018.

[16] M. Y. Vardi, "Is information technology destroying the middle class?". Communications of the ACM, vol. 58, no. 2, p. $5,2015$.

[17] L. Glanville, "The Myth of "Traditional" Sovereignty," Int Stud Q, vol. 57, no. 1, pp. 79-90, 2013, doi: 10.1111/isqu. 12004 .

[18] J. S. Barkin and B. Cronin, "The state and the nation: changing norms and the rules of sovereignty in international relations," International organization, vol. 48, no. 1, pp. 107-130, 1994.

[19] UNGA Resolution, "Declaration on the Inadmissibility of Intervention in the Domestic Affairs of States and the Protection of their Independence and Sovereignty," The American Journal of International Law, vol. 60, no. 3, p. 662, 1966, doi: 10.2307/2197280. 
[20] United Nations, Security Council Committee established pursuant to resolution 1970 (2011) concerning Libya | United Nations Security Council. [Online]. Available: https://www.un.org/securitycouncil/sanctions-committees/security-council-committee-established-pursuant-resolution-1970-2011-concerning (Accessed: 12 May, 2020).

[21] R. Grotenhuis, Nation-building as necessary effort in fragile States: Amsterdam University Press, 2016.

[22] T. S. Wu, "Cyberspace Sovereignty-The Internet and the International System," Harv. JL and Tech., vol. 10, p. 647, 1996.

[23] R. Capurro, Digital Ethics. In: The Academy of Korean Studies and Korean National Commission for UNESCO (Eds.):2010, 207-216.

[24] L. Floridi, "Soft Ethics and the Governance of the Digital," Philosophy and Technology, vol. 31, no. 1, pp. 1-8, 2018, doi: 10.1007/s13347-018-0303-9.

[25] A. AlHogail, "Improving IoT Technology Adoption through Improving Consumer Trust," Technologies, vol. 6, no. 3 , p. 64 , 2018, doi: 10.3390/technologies6030064.

[26] S. Teufel and B. Teufel, "The Positive Momentum of Crowds for the Implementation of Smart Environments," in Proceedings International Conference on Social Sciences and Management, Beijing, China, 2019, pp. 78-88.

[27] Y. Shiroishi, K. Uchiyama, and N. Suzuki, "Society 5.0: For Human Security and Well-Being," Computer, vol. 51, no. 7, pp. 91-95, 2018, doi: 10.1109/MC.2018.3011041.

[28] Z. Tufekci, We're building a dystopia just to make people click on ads. [Online]. Available: https://www.ted.com/talks/zeynep_tufekci_we_re_building_a_dystopia_just_to_make_people_click_on_ads? (Accessed: 11 May, 2020).

[29] S. Russell, Human compatible: Artificial intelligence and the problem of control: Penguin, 2019.

[30] M. Lindner, "Wenn der Hacker Spitalpatienten mitbehandelt," Neue Zürcher Zeitung, 2017, 2017. https://www.nzz.ch/digital/computervirus-wanna-crywenn-der-hacker-mitbehandelt-ld.1294555 (Accessed: 12 May, 2020).

[31] S. Teufel and B. Teufel, "Crowd Energy Information Security Culture - Security Guidelines for Smart Environments," in 2015 IEEE International Conference on Smart City/SocialCom/SustainCom (SmartCity), 2015, pp. 123128.

[32] J. Vasauskaite, S. Teufel, and B. Teufel, "Smart Framework: Application under the Conditions of Modern Economy," EE, vol. 28, no. 2, 2017, doi: 10.5755/j01.ee.28.2.17631.

[33] K. Schwab, The Fourth Industrial Revolution: what it means and how to respond. [Online]. Available: https://www.weforum.org/agenda/2016/01/the-fourth-industrial-revolution-what-it-means-and-how-to-respond/ (Accessed: 12 May, 2020). 